\title{
Moral Disengagement, Time Pressure and Academic Misconduct
}

\author{
Jia LIU* \\ Graduate School \\ Central University of Finance and Economics \\ Beijing, 10081 \\ China \\ ORCID: https://orcid.org/0000-0002-0542-1993
}

\begin{abstract}
Scientific research is a process of pursuing truth. However, in recent years, academic misconduct has become a common and insurmountable problem in academia. Academic research has begun to focus on academic misconduct. Existing research explored competitive pressures, conflicts of interest, and irrational academic evaluation systems are external factors that generate academic misconduct. However, these external factors are not enough to cause academic misconduct, and the lack of personal scientific research ability and low moral level are the inherent factors of academic misconduct.
\end{abstract}

Recent research on behavioral ethics and limited morality has pointed out the limited quality of ethical decisionmaking, that is, decision-makers with high moral standards may not be able to make fully rational ethical decisions (Bazerman, 2008; Reynolds,2010). The above external factors are just the inducement of academic misconduct. Only through moral disengagement can scientific researchers finally "convince" themselves to engage in academic misconduct with a clear conscience. Besides, time pressure will encourage this behavior to some extent.

Time is an important factor in the living environment. Every decision made by people is completed within a certain time limit. The adequacy of time has a very important impact on decision-making (Lin, 2005). However, with the development of society, the pace of life is accelerating, and time has become a rare resource for modern people, especially college students who are faced with completing dissertations and finding jobs in a limited time. Time pressure has become an indispensable part of students' lives, affecting their decisions all the time (Ackerman, 2003).

\section{Moral Disengagement and Academic Misconduct}

People usually have the ability to self-examination, and they can control their thoughts, emotions, motivations and actions. According to Bandura's theory of self-regulation, people's behavior is not only driven by external factors, but most of them are based on their own internal rules and self-evaluation of their actions to regulate their responses. Once an individual's ethical standards are in place, they will guide or hinder individual behavior. Individuals compare behavioral results with ethical standards, engage in behaviors that bring self-satisfaction or a sense of value and avoid those can violate moral standards and bring guilt.

For scientific researchers and college students, they have received ideological and political education, have the minimum academic accomplishment and academic misconduct obviously deviates from the academic moral standards. According to the above theory, they can completely stifle or correct academic misconduct through the self-regulation mechanism. However in reality, academic misconduct problem is getting worse. Why didn't their self-regulation system prevent their academic misconduct behavior?

Literature has shown that moral disengagement can selectively activate or deactivate self-regulating functions. The moral disengagement is a specific cognitive tendency produced by an individual, including reconstructing his behavior to make it less harmful, minimizing his responsibility in the consequences of the behavior, or reducing the suffering of the victim of his behavior, so that free themselves from self-punishment. This explains why students haveacademic misconduct in dissertations.

Moral disengagement cut off contact between academic misconduct and self-punishment, and the self-regulation process will be invalidated. When an individual violates its internal moral standards, for example, a student have academic misconduct behavior, his moral self-regulation can be invalidated through moral disengagement, which can make him rid of guilt and self-blame caused by academic misconduct.

\section{Time Pressure and Academic Misconduct}

A study researched the time pressure from the physiological point of view. They believe that time pressure is related to the individual's physiological response (Cangelosi \& Dill, 1965). When the individual feels the time pressure, it will produce some specific physiological reactions (Beldona, 2010). 
Once an individual is in a time-limited context, time pressure induces an individual's emotional changes, which in turn affects the individual's perceptions and decisions (Levav,2009). In the process of studying the influence of time pressure on individual decision-making, the researchers found three ways of responding to time pressure: First, under time pressure, individuals will speed up the processing of information, which may cause them to ignore certain important information. For example, students may ignore the possible consequences of academic misconduct. Second, time pressure causes anxiety in individuals. For graduate students or college students, they always felt that the time to complete their studies is short, and they have little time to think. Emotions are always in a state of high anxiety, which reduces the quality of decision-making, so it is possible to make adverse or unethical decisions. Third, consumers may change their decision-making strategies under time pressure. A large number of researches have shown that under time pressure, individuals will change from compensation decision rules to noncompensatory decision rules. Time pressure makes individuals more conservative in low-risk decisions, more risky in high-risk decisions. Academic misconduct is such a high-risk decision, which can greatly relieve the time pressure of students.

\section{What Can We Do}

Almost all the universities are continuously conducting honesty education for students. This is not only to prevent students from cheating and academic misconduct, but also to make students honest, trustworthy and upright. From my point of view, we can see that moral factors and students' ability to withstand stress may be important internal factors affecting academic misconduct. Therefore, honesty education is a long-term project. It should not only pass on the positive energy to students, but also pay attention to the psychological of moral evasion and time management ability.

According to the opinions in this article, the management of academic misconduct can not only start with improving the individual's scientific research quality and the scientific environment, but also find countermeasures from the aspects of moral disengagement and time pressure. Moral disengagement makes students' moral standards unable to restrain academic misconduct. If the tendency of moral disengagement can be reduced within the education process, academic misconduct can be reduced or even eliminated. In addition, if the management mechanisms such as thesis defenses and degree awarding of universities can be appropriately reformed, without limiting students' research time and breaking the inherent time pressure, academic misconduct can be effectively prevented.

\section{Funding}

The article is funded by MOE (Ministry of Education in China) Project of Humanities and Social Sciences, Graduate Education Innovation Fundand Party Building Project in Central University of Finance and Economics.

\section{Reference}

[1] Ackerman D. S., Gross B. L. So Many Choices, So Little Time: Measuring the Effects of Free Choice and Enjoyment on Perception of Free Time, Time Pressure and Deprivation [J]. Advances in Consumer Research, 2003(30):290-294 .

[2] Bandura, Albert. Social cognitive theory of self-regulation [J]. Organizational Behavior \& Human Decision Processes, 1991, 50(2):248-287.

[3] Bazerman, M. H., \& Moore, D. A. (2008). Judgment in managerial decision making (7th). Hoboken, NJ: John Wiley \& Sons.

[4] Beldona S, Moreo A P, Mundhra G D. The role of involvement and variety-seeking in eating out behaviors[J]. International Journal of Contemporary Hospitality Management, 2010, 22(3): 433-444.

[5] Detert, James R, Trevi?o, Linda Klebe, Sweitzer, Vicki L. Moral disengagement in ethical decision making: A study of antecedents and outcomes.[J]. Journal of Applied Psychology, 93(2):374-391.

[6] Janice Payan,James Reardon,Denny E.McCorkle.The Effect of Culture on the Academic Honesty of Marketing and Business Students[J].Journal of Marketing Education,2010.32(3): 275-291.

[7] Levav J, Zhu R. Seeking freedom through variety[J]. Journal of Consumer Research, 2009, 36(4): 600-610.

[8] Lin, C. H., Wu P. H.: "How to Deal With Conflicts? The Effect of Consumers' Subjective Time Pressure on Product Attitude Judgment and Choice". The Journal of American Academy of Business, 2005(3): 219 224.

[9] Reynolds, S. J. , Leavitt, K. , \& Decelles, K. A. . (2010). Automatic ethics: the effects of implicit assumptions and contextual cues on moral behavior. Journal of Applied Psychology, 95(4), 752-760.

[10] Xin Guo.Understanding Student Plagiarism: An Empirical Study in Accounting Education[J].Accounting Education: an international journal,2011(11) Vol.20:17-37. 